\title{
Timing of slip across the South Tibetan detachment system and Yadong-Gulu graben, Eastern Himalaya
}

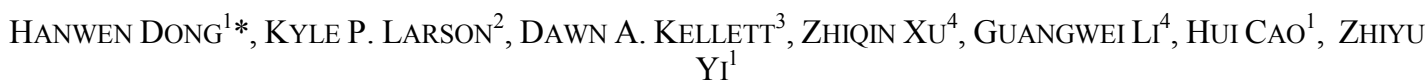

${ }^{1}$ Key Laboratory of Deep-Earth Dynamics of Ministry of Natural Resources, Institute of Geology, Chinese Academy of Geological Sciences, Beijing, 10037, China

${ }^{2}$ Earth and Environmental Sciences, IKBSAS, University of British Columbia Okanagan, 3333 University Way, Kelowna, BC V1V 1V7, Canada

${ }^{3}$ Geological Survey of Canada, Natural Resources Canada, 1 Challenger Drive, Dartmouth, NS B2Y 4A2, Canada

${ }^{4}$ School of Earth Science and Engineering, Nanjing University, Nanjing, 210023, China

The Himalayan orogen is the largest active continent-continent orogen on Earth and is generally regarded as the type-example for this style of collision. Despite the predominance of ongoing north-south convergence between the Indian and Eurasian continents, two major sets of extensional structures occur in the orogen, found in southern and/or central Tibet. One such set of structures comprises the South Tibetan detachment system (STDS), a family of approximately east-striking, shallowly to moderately north-dipping normal-sense faults and shear zones that have been traced along ca. $2000 \mathrm{~km}$ the length of the Himalayan system. The second set of extensional structures includes numerous, middle Miocene to recent north-south striking rifts (NSSRs) within the Tibetan plateau that accommodate(d) east-west extension. Detailed information on the timing of movement across the different sets of extensional structures is key to understanding the kinematic relationships between them.

The Yadong-Gulu graben, one of the NSSRS, provides an opportunity to evaluate the kinematic and temporal relationships between east-west directed extension in southern Tibet and north-south extensional strain in the Himalaya. In the Yadong region, distinct upper and lower top-down-to-the-north segments of the South Tibetan detachment system (STDS) are recognized. New U-Pb zircon geochronology demonstrates that the cessation of the Yadong shear zone, the structurally lower, ductile portion of the STDS, occurred ca. $20 \mathrm{Ma}$ and that motion along the structurally higher brittle-ductile Zherger La detachment continued after ca. 16.6 Ma. This new age is compatible with the similar structures in nearby Everest-Sikkim and indicates that the STDS was laterally continuous across the Everest-SikkimYadong portion of the Himalayan orogen. Cooling paths outline distinct early and late Miocene cooling stages. We suggest that these two stages related to N-S and E-W extension, respectively. The second cooling stage (14 5 Ma) specifically is interpreted to define the onset of the Yadong-Gulu graben, which represents a minimum age for the STDS it offsets. Our data, combined with published geochronologic constraints, demonstrate that the Yadong-Gulu rift system generally propagated progressively towards the north, with segments such as that in the Yadong region, locally propagating in the opposite direction. 